\title{
Sexual Knowledge and Practices of Students of Senior High Schools in the Bolgatanga Municipality, Ghana
}

\author{
Mahama Mubarik $^{1^{*}}$, Oladokun Michael Yemisi ${ }^{2}$ \\ ${ }^{1}$ Physical Education Unit, Gbewaa College of Education, Pusiga, Ghana \\ ${ }^{2}$ Physical Education Unit, St John Bosco's College of Education, Navrongo, Ghana \\ Email: mahamamubarik4@gmail.com
}

Received: 9 September 2020; Revised: 26 April 2021; Accepted: 26 April 2021

\begin{abstract}
The purpose of this study was to investigate the extent of knowledge students of senior high schools in Bolgatanga, the Upper East Regional capital of Ghana, have on risky sexual behaviours and also to seek for answers on the reasons why students engaged in or will engage in sexual practices. Multistage sampling technique was employed to sample 400 students from the four public senior high schools in the municipality to respond to a researcher-designed instrument. Descriptive statistical analyzes were used in order to analyze the two research questions. The results suggest that majority of the respondents demonstrated moderate to high level of knowledge on sexual risk-taking behaviour $(21 \%$ and $68 \%$ respectively). Moreover, the students indicated expression of love, to make money and to boost once social status as part of the varied reasons that influenced or would influence them to engage in sexual intercourse. The study concludes that the students will protect themselves against contracting sexually transmitted infections (STI), thereby reducing the incidence of HIV and female students might also be involved in multiple-partnered sexual relations.
\end{abstract}

Keywords: sexual behaviour, sexuality, municipality, knowledge

\section{Introduction}

Globally, adolescent sexual risk-taking behaviour has been a major challenge. The entire world records more than one million curable sexually transmitted infections (STIs) every single day (WHO, 2018). The global body estimates that about 376 million new infections of the four curable STIs-chlamydia, gonorrhea, syphilis and trichomoniasis- were recorded in 2016 (WHO, 2018). This is supported by trends towards larger numbers of inconsistent condom use with new partners (Choudhary et al., 2015), early sexual debut, multiple sexual partnerships (Gravningen et al., 2012), use of alcohol/drug before sex (O'Hara \& Cooper, 2015) and commercial/transactional/paid sex (Choudhary et al., 2015).

Adolescents have some inherent and psychological needs such as need for sex, social recognition and food, of which the need for sex is one of the prominent needs adolescents seek for psychological satisfaction (Awabil et al., 2009). Sexuality, therefore, plays a critical role in the upbringing of adolescents.

A study conducted among Portuguese adolescents in college revealed that majority of the students have moderate/ high level of knowledge in STIs but boys and young men showed bigger risk acceptance while girls demonstrated better knowledge in relation to risk-taking (Ramiro et al., 2012).

A similar study conducted in China revealed a significantly higher knowledge on all the modes of transmission (drug

Copyright (C2021 Mahama Mubarik, et al.

DOI: https://doi.org/10.37256/ser.222021679

This is an open-access article distributed under a CC BY license

(Creative Commons Attribution 4.0 International License)

https://creativecommons.org/licenses/by/4.0/ 
use by intravenous injection, mother to child transmission and unprotected sex) of HIV/AIDS from students who live in urban areas than those from rural areas. However, the study further revealed that the proportion of Chinese female college students who were privileged to receive safe-sex education before enrolling in university from rural areas was significantly lower than the proportion of students from urban areas (Chen et al., 2016).

A study conducted in an Irish University meant to test the HIV/ADS knowledge, behaviour and attitudes among undergraduate students also supported the results of several other studies that students have moderately high knowledge about HIV/AIDS and sexual behaviour (Choudhary et al., 2015).

On the danger of sexual victimization by rape or coercion, Budu et al. (2021) in a study conducted using the Demographic and Health Survey in 31 countries in Sub-Saharan Africa between 2010 and 2019 revealed that women in Congo DR, Nigeria, Burundi and Niger who experienced early marriage were less likely to have sexual autonomy. This is because girls who got married early may lack the ability to speak out for their sexual rights since their male partners take most of the decisions at home, including decisions of sex. There is, therefore, the need to support the relevance of women's autonomy, education and exposure in order to address the lack of knowledge on HIV/AIDS (Iqbal et al., 2019).

Sexual violence is seen as a major violation of human rights which affects mainly young men and adolescents. Most adolescents who are sexually abused go through mental illness simply because their perpetrators either make them pregnant or infect them with STI (Blake et al. 2014). They also revealed that rape cases among vulnerable people were almost four times more common among adolescents.

The HIV Sentinel Survey Report released by the Ghana AIDS Commission (GAC) disclosed that HIV is mostly transmitted through unprotected heterosexual contact (Ghana AIDS Commission, 2014). The Commission further indicated that the Bolgatanga municipality recorded an HIV prevalence rate of 3.8\% in 2010 (Ghana AIDS Commission, 2012). This prevalence rate is due to the increasing trend in promiscuity, the explosion of new tertiary institutions in the area and the proximity of Bolgatanga to neighboring countries like Burkina-Faso, Mali and Togo as some causes for the increase in HIV prevalence rates (Bruce-Quansah, 2011).

Although some advances have been made in the study of sexual behaviour and risky sexual behaviour in Ghana and Bolgatanga in particular, there are still critical gaps of information and published data on the phenomena. Geugten et al. (2017) examined knowledge level of youths in Bolgatanga Municipality on contraceptives, STIs and pregnancy whilst Geugten et al. (2015) conducted a research within the junior and senior high school student population of the Bolgatanga community, in Northern Ghana, to learn about students' knowledge, attitude and behaviour of sexual and reproductive health of this adolescent student population.

These gaps in the literature justify the need for a deeper examination and understanding of issues concerning knowledge level on risky sexual behaviour as well as reasons why adolescents engage in sexual intercourse.

The purpose of this study was meant to seek for answers on the reasons why students engaged in or will engage in sexual practices. The study was also to investigate the extent of knowledge students of senior high schools in Bolgatanga have on risky sexual behaviours that have the tendency of infecting them with sexually transmitted diseases.

The research posed and examined the following research questions:

1. What reasons do students of senior high schools in the Bolgatanga Municipality give for engaging in sexual intercourse?

2. What is the knowledge level of students of senior high schools in Bolgatanga on sexual risk-taking behaviours?

\section{Methodology}

The descriptive survey design was utilized for the study. The design was chosen because of its advantage on producing good amount of responses from a wide range of people (Creswell, 2014). The population of the study was all the students of the four public senior high schools in the Bolgatanga municipality. The four public schools included Zuarungu Senior High School (ZUSS), Zamse Secondary Technical School (ZAMSTECH), Bolgatanga Girls Senior High School (BOGISS) and Bolgatanga Technical Institute (BOTECH).

According to the figures the researcher gathered from the assistant head teachers of the various institutions, the total population of all the four public schools was 4008 which comprised 1141 from BOGISS, 954 from BOTECH, 823 from ZUSS and 1090 from ZAMSTECH. This number is made up of only the first-year and second-year students who 
happened to be the only group of students on the various campuses. The final-year students wrote the West Africa Senior School Certificate Examination and had therefore left the school.

Multistage sampling technique was used to sample 400 students. This was based on an assertion made by Krejcie and Morgan (1970) in their table of determining sample size. Krejcie and Morgan (1970) opined that if the population is 4000 , then the sample size should be 351 .

In order to sample a proportional number of students from all four schools, $10 \%$ of the students in each school were calculated, and the results were rounded up to arrive at the sample size of 400 . Sample size of 400 was therefore chosen since it represents about $10 \%$ of the entire population which is a fairly good representation of the entire population. The $10 \%$ of the population of each school meant that the accessible population included 114 students from BOGISS, 109 students from ZAMSTECH, 82 students from ZUSS and 95 students from BOTECH.

Purposive sampling technique was used to select the four public schools in the Bolgatanga municipality. Simple random technique was employed to select the programme of study from each form. Systematic random sampling technique was then used to select the individual respondents from each school. This was because students sit in class according to their programme of study and so it was always easy to have access to them and their register any time they need arose.

The researchers used the bowl method to randomly select a programme after closing the eyes and shaking the bowl to mix the papers containing names of programmes offered in form 1 . The same process was replicated in selecting the desired programmes for the form 2 classes. For instance, out of the ten programmes offered at Bolgatanga Technical Institute, simple random sampling was employed to select only one programme for form 1-Catering programme and Carpentry and Joining for form 2. The same process was replicated in the selection of programmes from the rest of the schools.

The next stage was to select the individual respondents from the selected programmes of study. A programme of study in all four schools had average student population of about 140 scattered in different classes. So systematic random sampling was used to select 114, 109, 82 and 95 from BOGISS, ZAMSTECH, ZUSS and BOTECH respectively.

In using the systematic random sampling, the class register for a selected programme was used to number the students from the first to the last person. The interval size $\mathrm{k}$ was then calculated to determine the kth unit from the first member and every other kth unit followed next (Ogah, 2013). The interval size of 3 was calculated to select the units. The students sampled after the systematic random sampling were assured of the confidentiality of the study after which the questionnaire was administered.

The main instrument for the study was a self-structured questionnaire. The questionnaire consisted of 17 closeended items which were sub-divided into 3 parts: sections A, B and C. In the section A, respondents were assessed on their level of knowledge on sexual risk-taking behaviours whilst section B demanded of the respondents to tick as many as possible any of the eight listed reasons why they engaged in sexual intercourse. Meston and Buss (2007) discovered about 145 reasons why adolescents engage in sex. They further grouped the reasons into four main areas: physical reasons, goal attainment reasons, emotional reasons and insecurity reasons. The eight listed reasons were picked from the four main reasons simply because of time and resources constraints in listing the 145 reasons for respondents to choose and for further analyses. The last section questioned the students on their personal demographic data.

This instrument was pilot tested at Kongo Senior High School which had similar characteristics as the four public senior high schools sampled. This enabled the researchers to assess the validity and reliability of the instrument. Furthermore, during the administration of the questionnaire, all questionnaire that were seen to be incomplete were given back to the respondents to complete. This ensured that the researchers had a $100 \%$ response rate.

\section{Results}

The sexual behaviour pattern among respondents in senior high schools in Bolgatanga who were sexually active was $57 \%(\mathrm{~N}=400)$ while the rest $(\mathrm{n}=172)$ live celibate lifestyle. 


\subsection{Research question 1: What reasons do students of senior high schools in bolgatanga give for engaging in sexual intercourse?}

This first research question seeks to find out the reasons why adolescents in senior high schools in the Bolgatanga Municipality engaged in or will engage in sexual intercourse. The results are presented in Table 1 . The study revealed that $51 \%$ of the respondents engaged in or will engage in sexual intercourse because of the physical attractiveness of the sexual partners whilst $50 \%$ of the students also indicated physical and emotional pleasure as the reason that influenced or will influence them to engage in sexual intercourse. Additionally, $42 \%$ and $43 \%$ of the respondents engaged in or will engage in sexual intercourse to please their friends and to make money respectively. Interestingly, reasons such as being pressured into having sex, to boost social status and to prevent a break-up each received $40 \%$ response rate whilst $64 \%$ of the respondents indicated the expression of love for the sexual partner as the reason that made or will make them engage in sexual intercourse.

According to Table $1,64 \%(n=256)$ of the respondents engaged in or will engage in sexual intercourse with a partner because they want to express their love and affection for the partner. This notion is also shared by Gangestad and Simpson (2000). In contributing to this issue, Buss (2003) asserted that having a sexual relationship with a loved person can turn a short-term relationship into a long-term relationship. Research also proves that women who receive "spin-offs" such as emotional closeness, bonding, commitment, love, affection and tolerance from others easily agree to have sexual intercourse with such people (Buss, 2003).

Table 1 also depicts that majority (51\%) of the respondents confirmed that they had or will have sexual intercourse because of the physical attractiveness of the partner. This result is consistent with the National Survey of Australia (2002) who opined that $93 \%$ of young people indicated physical attractiveness as being the bases for which they engaged in sexual intercourse with their partners.

William Masters and Virginia Johnson in their study in 1966 espoused that the orgasm phase of the sexual response cycle is associated with highly intense and pleasurable release of tension (Huffman, 2007). This explains why 204 (51\%) of the respondents engaged in or will engage in sexual intercourse because of the physical and emotional pleasure (see Table 1). Browning et al. (2000) supported this viewpoint by indicating that sexual intercourse for pleasure is associated with frequent sex.

Table 1. Reasons for students of senior high schools in bolgatanga giving for engaging in sexual intercourse

\begin{tabular}{cccc}
\hline Reasons for Having Sex & Yes & No & Total \\
\cline { 2 - 4 } Physical attractiveness of partner & No. (\%) & No. (\%) & No. (\%) \\
\hline To experience physical and emotional pleasure & $204(51)$ & $196(49)$ & $400(100)$ \\
To please my friends & $201(50)$ & $199(50)$ & $400(100)$ \\
To make money & $168(42)$ & $232(58)$ & $400(100)$ \\
To prevent a breakup & $172(43)$ & $228(57)$ & $400(100)$ \\
To boost my social status & $160(40)$ & $240(60)$ & $400(100)$ \\
Pressured into having sex & $160(40)$ & $240(60)$ & $400(100)$ \\
To express my love for the person & $160(40)$ & $240(60)$ & $400(100)$ \\
\hline
\end{tabular}

The reason why students engaged in or will engage in sexual intercourse was examined to ascertain association with gender. Regarding the gender of the respondents, $56 \%(\mathrm{~N}=400)$ of the students are girls whilst the remaining $44 \%$ $(n=176)$ are boys. The results of the association can be found in Table 2.

A cross-tabulation of gender and reasons why students will engage in or engaged in sexual intercourse revealed 
that more girls than boys cited physical attractiveness as the reason for which they will engage in or engaged in sexual intercourse (see Table 2). As depicted in Table 2, 54\% of girls reported that they will engage in or engaged in sexual intercourse because of physical attractiveness of their sexual partner, while $46 \%$ of the boys engaged in or will engage in sexual intercourse because of the physical attractiveness of the sexual partner. A chi-square test of independence revealed there was no statistically significant difference between boys and girls in physical attractiveness as a reason of engaging in sexual intercourse $[\chi 2(1, \mathrm{n}=400)=0.4262$, Probability $=0.514]$.

Experiencing sexual pleasure which is one of the reasons why students engaged in or will engage in sexual intercourse was also examined to ascertain association with the gender of the students. As shown in Table 2, 85 of the male respondents indicated that they engaged in or will engage in sexual intercourse because of sexual pleasure while 116 female respondents engaged in or will engage in sexual intercourse because of sexual pleasure. However, a chi-square test of independence revealed there is no statistically significant difference between boys and girls in experiencing sexual pleasure as a reason of engaging in sexual intercourse and the gender of the students $[\chi 2(1, n=400)$ $=0.4803, \operatorname{Pr}=0.488]$. This result is in contrast with Saaka (2005) who found that more boys were influenced into sexual intercourse because of the erotic sensation and pleasure derived from sexual intercourse.

Engaging in sexual intercourse in exchange for money was cross-tabulated with gender. As depicted in Table 2 , more girls $(63 \%)$ reported that they engaged in or will engage in sexual intercourse for money than their male counterparts. A chi-square test of independence revealed a statistically significant difference between boys and girls in relation with engaging in sexual intercourse for money $[\chi 2(1, \mathrm{n}=400)=5.2375, \operatorname{Pr}=0.022]$. This is consistent with several other studies which revealed that more girls than boys engage in sexual intercourse for money or material gains (Fayorsey, 2002; Luke, 2005; Menda, 2006). Menda (2006) further asserted that other qualitative studies conducted in Cameroon, Ghana, Kenya, Nigeria, Sierra Leone, Uganda, and Zimbabwe suggested that peer pressure to obtain luxury personal items motivates many female adolescents to engage in transactional sex.

Table 2 also shows the association between the gender of high school students in Bolgatanga Municipality and being forced into having sexual intercourse. The study revealed that more girls (54\%) engaged in or will engage in sexual intercourse when forced while their male counterparts reported $74(46 \%)$ respondents. A chi-square of independence showed no statistically significant difference between gender and being forced into having sexual intercourse $\left[\chi^{2}(1, \mathrm{n}=400)=0.4213, \mathrm{Pr}=0.516\right]$. This result is consistent with similar studies where in Ghana one in four sexually experienced young women say that they have ever been forced to have sexual intercourse ( $8 \%$ of sexually experienced young men report the same). Furthermore, a study conducted in Ghana by Guttmacher Institute (2005) revealed that $30 \%$ of females and $16 \%$ of males between $15-19$ years who have ever had sex attributed being tricked or forced into sex as one of the reasons why they engaged in sexual intercourse (Awusabo-Asare et al., 2006).

Table 2. Gender differences in student reasons for having sex

\begin{tabular}{|c|c|c|c|c|c|c|}
\hline \multirow{2}{*}{ Reasons for Having Sex } & \multicolumn{2}{|c|}{ Male } & \multicolumn{2}{|c|}{ Female } & \multirow{2}{*}{$\chi^{2}$ Value } & \multirow{2}{*}{ Sig Value } \\
\hline & No. & $\%$ & No. & $\%$ & & \\
\hline Physical attractiveness of partner & 93 & 46 & 111 & 54 & 0.4262 & 0.514 \\
\hline To experience physical and emotional pleasure & 85 & 42 & 116 & 58 & 0.4803 & 0.488 \\
\hline To please my friends & 65 & 38 & 104 & 62 & 4.1431 & 0.046 \\
\hline To make money & 64 & 37 & 107 & 63 & 5.2375 & 0.022 \\
\hline To prevent a breakup & 70 & 43 & 92 & 57 & 0.069 & 0.793 \\
\hline To boost my social status & 73 & 45 & 88 & 55 & 0.1968 & 0.657 \\
\hline Pressured into having sex & 74 & 46 & 87 & 54 & 0.4213 & 0.516 \\
\hline To express my love for the person & 108 & 43 & 146 & 57 & 0.6189 & 0.431 \\
\hline
\end{tabular}


A cross-tabulation of gender and engaging in sexual intercourse to express once love and affection to the partner also revealed that more girls (57\%) engaged in or will engage in sexual intercourse as a way of expressing their love and affection while $43 \%$ of the males will also do the same. A chi-square of independence did not, however, show any significant difference between the two sexes $[\chi 2(1, \mathrm{n}=400)=0.6189, \operatorname{Pr}=0.431]$. Bassoon (2000) contradicts the findings by revealing that women engage in sexual intercourse for the "spin-offs" they receive, such as emotional closeness, bonding, commitment, love, affection, acceptance, tolerance, and closeness but the love triangle espoused by psychologist Robert Sternberg in 1988 confirms the results that both men and women engage in sexual intercourse simply because they see it as a way of expressing their love and affection to their sexual partners (Insel \& Roth, 2004).

The results of the chi-square analysis revealed that there was no significant difference between gender and six of the reasons why the respondents will engage in or engaged in sexual intercourse (see Table 2). These six reasons include physical attractiveness, experience physical and emotional pleasure and to prevent break-up. The rest are to boost social status, to express love and affection and lastly being pressured into having sex.

\subsection{Research question 2: What is the knowledge level of students of senior high schools in bolgatanga on sexual risk-taking behaviours?}

This research question sought to find out the knowledge level of the respondents as far as sexual risk-taking behaviour is concerned. Figure 1 is a pie chart that clearly shows the knowledge level of the respondents concerning risky sexual behaviour. The results of Figure 1 show that majority of the respondents have high knowledge on sexual risk-taking behaviour. The findings also showed that only $11 \%(\mathrm{n}=44)$ of the respondents had at most 2 out of the 5 questions on sexual risk-taking behaviour right.

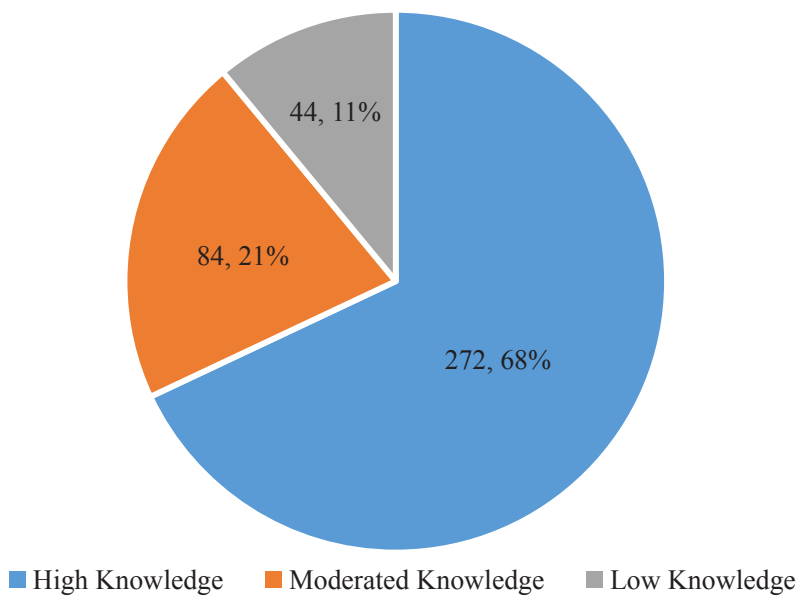

Figure 1. Knowledge level of risky sexual behaviours among senior high school students

\section{Discussions}

The results of research question one as depicted in Table 2 postulate that both boys and girls will engage in or engaged in sexual intercourse because of the love and affection that they have for their sexual partner. Most of these adolescents who have love and affection for their sexual partners are likely to engage in unprotected sexual intercourse (Buss, 2003). Such people are blindfolded with so much love and trust to the extent that they do not want to incur the displeasure of their sexual partner by insisting on the use of the condom. There is also the belief that for one to truly prove to the partner that he or she loves him or her, then there is the need for them to engage in sexual intercourse and in most cases unprotected sexual intercourse (Ondrej, 2012).

Rape or being pressured into having sexual intercourse is an ugly phenomenon that seems to be prevalent globally (Nanyonga, 2006). Recording almost half (40\%) of the respondents citing rape as a reason for engaging in sexual 
intercourse means that the issue should be given special attention. Most of these rapists physically abuse their victims and infect them with sexually transmitted infections. There is the need to render stiffer punishments to people found guilty of rape.

There was, however, significant difference between gender and two other reasons why adolescents engage in or will engage in sexual intercourse to please friends and to make money (see Table 2).

The desire of women to acquire material possession leads them to exchange sex for money or gifts (Illingworth, 2004). According to Johnson and Budlender (2002), most women engage in unprotected sex in order to earn a living. This will lead to the contraction of HIV and STD infection (Gibney et al., 2002).

The study also revealed that there was significant difference between gender and having sexual intercourse to please friends (see Table 2). Research has indicated that most male adolescents are influenced by their peers to engage in sexual intercourse (Luke, 2005). A study in Botswana revealed that majority of men aged 15 to 19 reported to be sexually active with more than one sexual partners (Palai et al., 1991). It is therefore prudent to involve peers of adolescents during health promotion campaigns.

The results of research question two corroborate with De Walque (2009) report that almost all the high school students in San Francisco were aware of sexual risk-taking behaviours that could lead to HIV infection. There are several other studies that supported the view that adolescents in high schools have moderately high knowledge on sexual risk-taking behaviours that have the tendency of infecting them with HIV/AIDS and other STIs (Bana et al., 2010; Gerend \& Magloire, 2008). The high knowledge exhibited by adolescents in college could be attributed to the fact that information on sexual health can easily be accessed by the adolescents through the television, the radio, the internet and their peers (Nundwe, 2012). Nundwe (2012) is also of the view that the parents of adolescents avoid talking to their children about sex simply because they (parents) fear that any discussion on sex can lead the children into sexual experimentation. Nundwe (2012) adds that there is the need for parents to monitor their children because not everything they come across in the social media is correct and misinformation abounds. So in as much as adolescents can access correct information on sexual health from the mass media, there is the tendency of also consuming wrong information that could go a long way to put their (adolescents) lives at risk of STIs.

Baiden and Rajulton (2011) also think that the increase in the quality and quantity of knowledge on avoidance of risky sexual behaviour and HIV infection over the past decade has not translated in safe and responsible sexual behaviour practices. They add that behavioural change among Ghanaian youth is yet to correspond with the amount of information and education provided. There is, therefore, the need for policy makers and other stakeholders in health promotion to go beyond mere health education talks to institute measures that will motivate adolescents to utilize the knowledge they (adolescents) have acquired as far as protecting their health is concerned.

The fact that only 44 (11\%) respondents have low knowledge on risky sexual behaviour should not be taken lightly since their ignorance can lead to the spread of STIs. This is because an adolescent who has low knowledge on the mode of HIV transmission can unknowingly transmit the virus to his or her sexual partner(s).

\section{Limitations of the study}

Although painstaking efforts were made to acquire every bit of information needed to conduct this research, there were still a few limitations that need to be acknowledged.

Firstly, the study was intended to assess sexual knowledge and practice of senior high school students in the Bolgatanga municipality. However, due to the absence of third-year students, they were not included in the study. Admittedly, results from the third-year students could have enriched the study if they were included in the study. In addition, choosing only 400 respondents from a target population of 4008 may have an effect on the validity of the result.

Secondly, some of the students were reluctant to answer some of the questions. They did not want to choose certain answers that will expose their sexual behavior to the researcher and their peers who sat closer to them. There was, therefore, the tendency of providing bias responses. According to Zaba et al. (2004), such biases could occur through women under-stating and men over-stating their levels of sexual behavior practices. 


\section{Conclusion}

The purpose of this study was meant to seek for answers on the reasons why students engaged in or will engage in sexual practices. The study was also to investigate the extent of knowledge students of senior high schools in Bolgatanga have on risky sexual behaviours that have the tendency of infecting them with sexually transmitted diseases.

It emerged from the study that the students have high knowledge on sexual risk-taking behaviour. It may be concluded that the students will protect themselves against contracting STIs thereby reducing the incidence of HIV, Syphilis or Gonorrhoea.

It may also be inferred from the analysis that female students in senior high schools might be involved in multiplepartnered sexual relations. This is to enable them to access money and other material possessions from their numerous sexual partners.

\section{Recommendations}

There is the need to intensify their health promotion campaigns especially on sexual risk-taking behaviours so as to ensure that the few students who have low knowledge on sexual risk-taking behaviour can also become much more knowledgeable.

Ghana Health Service and other non-governmental organizations should periodically make available condoms to be distributed freely to the students.

Parents and guardians should show much interest in their female wards education and development. This will ensure that female students in senior high schools do not engage in sexual intercourse because of money.

\section{References}

Awabil, G., Turkson, B. A., Bisi, O., Badu, G. K., \& Bukari, N. (2009). Adolescent pregnancy in Ghana: Contributory factors, consequences and counseling implications. Ghana Journal of Health, Physical Education, Recreation and Dance, 1(2), 120-133.

Awusabo-Asare, K., Biddlecom, A., Kumi-Kyereme, K., \& Patterson, K. (2006). Adolescent sexual and reproductive health in Ghana: Results from the 2004 national survey of adolescents. New York: The Alan Guttmacher Institute.

Baiden, P., \& Rajulton, F. (2011). Factors influencing condom use among women in Ghana: An HIV/AIDS perspective. Sahara J, 8(2), 46-54.

Bana, A., Bhat, V., Godlwana, X., Libazi, S., Maholwana, Y., Marafungana, N., Mona, K., Mbonisweni, A., Mbulawa, N., Mofuka, J., Mohlajoa, N., Nondula, N., Qubekile, Y., \& Ramnaran, B. (2010). Knowledge, attitudes and behaviours of adolescents in relation to STIs, pregnancy, contraceptive utilization and substance abuse in the Mhlakulo region, Eastern Cape. South African Family Practice, 52(2), 154-158.

Basson, R. (2000). The female sexual response: A different model. Journal of Sex and Marital Therapy, 26, 51-65.

Blake, M. D. T., Drezett, J., Vertamatti, M. A., Adami, F. Valenti, V. E., Palva, A. C., Viana, J. M., Pedroso, D., \& Abreu, L. C. D. (2014). Characteristics of sexual violence against adolescent girls and adult women. BMC Women's Health. 14,15 .

Browning, J. R., Hatfield, E., Kessler, D., \& Levine, T. (2000). Sexual motives, gender and sexual behaviour. Archives of Sexual Behaviours, 29, 135-153.

Budu, E., Ahinkorah, B. O., Seidu, A.-A., Hagan, J. E., Jr., Agbemavi, W., Frimpong, J. B., Adu, C., Dickson, K. S., \& Yaya, S. (2021). Marriage and Sexual Autonomy among women in Sub-Saharan Africa: Evidence from 31 Demographic and Health Surveys. International Journal of Environmental Research and Public Health, 18(7), 3754. https://doi.org/10.3390/ijerph18073754

Buss, D. M. (2003). The evolution of desire: Strategies of human mating. New York: Basic Books.

Chen, M., Liao, J., Liu, J., Fang, W., Hong, N., Ye, X., Li, J. J., Tang, Q., Pan, W., \& Liao, W. (2016). Comparison of sexual knowledge, attitude, and behaviour between female Chinese college students from urban areas and rural areas: A hidden challenge for HIV/AIDS control in China. BioMed Research International, 2016, 1-10 https://doi. org/10.1155/2016/8175921

Choudhary, H. A., Ali, R. A., \& Altaf, S. (2015). Knowledge, behaviour and attitudes regarding HIV/AIDS among 
undergraduate students in an Irish University. International Journal of Surgery and Medicine, 1(2), 58-66

De Walque, D. (2009). How does the impact of an HIV/AIDS information campaign vary with educational attainment? Evidence from rural Uganda. Journal of Development Economics, 84(2), 686-714.

Fayorsey, C. (2002). Knowledge, attitude and practice (KAP) on HIV/AIDS among students, teachers and parents in selected schools in Ghana: Key baseline findings. Accra, Ghana: World Education/Ghana.

Gangestad, S. W., \& Simpson, J. A. (2000). The evolution of human mating: Trade-offs and strategic pluralism. Behavioural and Brain Sciences, 23, 675-687.

Gerend, M. A., \& Magloire, Z. F. (2008). Awareness, knowledge, and beliefs about human papillomavirus in a racially diverse sample of young adults. Journal of Adolescent Health, 42(3), 237-242.

Ghana AIDS Commission (2014). 2014 Status report. Accra: Ghana Aids Commission.

Ghana AIDS Commission (2012). Ghana AIDS country progress report January 2010-December 2011. Accra: Ghana Aids Commission.

Geugten, J. V. D., Meijel, B. V., Uyl, M. H. G. D., \& Vries, N. K. D. (2017). Protected or unprotected sex: The conceptions and attitudes of the youth in Bolgatanga Municipality. Ghana. Sexuality and Culture, 21, 1040-1061.

Geugten, J. V. D., Meijel, B. V., Uyl, M. H. G. D., \& Vries, N. K. D. (2015). Evaluation of a sexual and reproductive health education programme: Students' knowledge, attitude and behaviour in Bolgatanga Municipality, Ghana. African Journal of Reproductive Health, 19(3), 126-136.

Gibney, L., Squib, N., Macaluso, M., Hasan, K. N., Aziz, M. M., Khan, A. Y. M. H., \& Choudhury, P. (2002). STD in Bangladesh's trucking industry: Prevalence and risk factors. Sexually Transmitted Infections, 78(1), 31-36.

Gravningen, K., Furberg, A-S. Simonsen, G. S., \& Wilsgaard, T. (2012). Early sexual behaviour and Chlamydia trachomatis infection-a population based cross-sectional study on gender differences among adolescents in Norway. BMC Infectious Diseases, 12(1), 319.

Guttmacher Institute. (2005). Conceptual framework of adolescent and reproductive health. In K. Awusabo-Asare, A. Biddlecom, K. Kumi-Kyereme \& K. Patterson (Eds.), Adolescent Sexual and Reproductive Health Survey of Adolescents (pp. 22). New York: Guttmacher Institute.

Huffman, K. (2007). Psychology in action (8th ed.). Boston: Hermitage Publishing Services.

Illingworth, B. (2004). Sugar daddies in Africa: The growing trend of transaction sex. Planned parenthood federation of America. http://www.plannedparenthood.org/pp2/portal/files.

Insel, M. P., \& Roth, W. T. (2004). Core concepts in health (9th ed.). New York: McGraw-Hill.

Iqbal, S., Maqsood, S., Zafar, A., Zakar, R., Zakar, R., Zakar, M. Z., \& Fischer, F. (2019). Determinants of overall knowledge of and attitudes towards HIV/AIDS transmission among ever-married women in Pakistan: evidence from the Demographic and Health Survey 2012-13. BMC Pubic Health, 19(1), 793. https://doi.org/10.1186/s12889019-7124-3

Luke, N. (2005). Are wealthy men spreading HIV? Exploring economic status, informal exchange and sexual risk in Kisumu, Kenya. A paper presented at the annual meeting of Population Association of America, Los Angeles, CA.

Menda, M. D. (2006). Assessment of sexual behaviour and knowledge of HIV amongst adolescent school girls in a rural district in Zambia. Unpublished Master's thesis. University of the Western Cape. http://hdl.handle.net/11394/1931

Moore, S., \& Rosenthal, D. (2006). Sexuality in adolescence: Current trends. Australia: Routledge.

Nanyonga, R. (2006). Sexual behavior among people living with HIV on Antiretroviral therapy at Mpigi. Health Centre IV, Central Uganda. Unpublished Master's thesis. http://hdl.handle.net/10570/2168

Nundwe, C. S. (2012). Barriers to communication between parents and adolescents concerning sexual and reproductive health issues: A Case Study of Kinondoni Municipality. Unpublished Master's Disertation. Muhimbili University of Health and Allied Sciences. https://core.ac.uk/display/11307885

Ogah, J. (2013). Decision making in the research process: Companion to students and beginning researchers. Accra: Adwinsa Publications.

O’Hara, R. E., \& Cooper, M. L. (2015). Bidirectional associations between alcohol use and sexual risk-taking behaviour from adolescence into young adulthood. Arch Sex Behav, 44, 857-871.

Ondrej, K. (2012). Sexual risky behaviour among Slovak adolescents and young adults: Social and psychological factors. Slovak Republic: Equilibria Press.

Palai, T., Letshwiti, E., \& Maswabi, M. (1991). Men, sex and AIDS. Gaborone: Ministry of Health.

Rondini, S., \& Krugu, K. J. (2009). Knowledge, attitude and practices on reproductive health among secondary school students in Bolgatanga, Upper East Region, Ghana. African Journal of Reproductive Health, 13(3), 51-66.

Saaka, S. S. (2005). HIV/STIs health-seeking behaviour among in-and out-of-school urban male adolescents in the Bolgatanga municipality of Upper East Region, Ghana. Unpublished Master's Dissertation. Kwame Nkrumah University of Science and Technology, Kumasi. https://www.academia.edu/1948090/HIV_STIs_health_seeking_ 
behaviour_among_in_and_out_of_school_urban_male_adolescents_in_the_Bolgatanga_Municipality_of_Upper_ East_Region_Ghana

World Health Organization. (2018). Global action plan on physical activity 2018-2030: More active people for a healthier world. Geneva: Switzerland.

Zaba, B., Pisani, E., Slaymaker, E., \& Boerma, T. J. (2004). Age at first sex: Understanding recent trends in African demographic surveys. Sexually Transmitted Infections, 80, 28-35. 